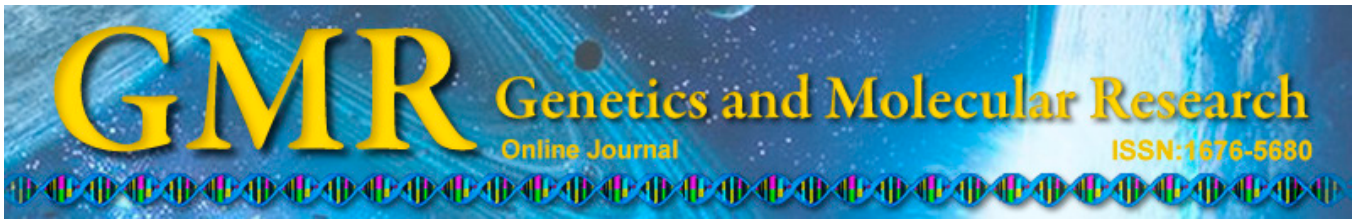

$\underline{\text { Short Communication }}$

\title{
Polymorphic microsatellite markers in the traditional Chinese medicinal plant Paris polyphylla var. yunnanensis
}

\author{
Y. Song ${ }^{1,2}$, M.F. Li ${ }^{1,2}$, J. Xu ${ }^{1,2}$, Z. Zhao ${ }^{1,2}$ and N.Z. Chen ${ }^{1,2}$ \\ ${ }^{1}$ Institute of Plant Quarantine, Chinese Academy of Inspection and Quarantine, \\ Beijing, China \\ ${ }^{2}$ Biological Germplasm Resources Identification Center, \\ Administration of Quality Supervision, Inspection and Quarantine of China, \\ Beijing, China \\ Corresponding author: Y. Song \\ E-mail: sydef1016@163.com
}

Genet. Mol. Res. 14 (3): 9939-9942 (2015)

Received April 16, 2015

Accepted June 26, 2015

Published August 19, 2015

DOI http://dx.doi.org/10.4238/2015.August.19.29

\begin{abstract}
Paris polyphylla var. yunnanensis is a traditional Chinese medicinal plant and is listed as vulnerable by the IUCN. This medicinal herb is well known for its analgesic and antiinflammatory properties, most notably as an ingredient of the hemostatic compound "Yunnan Baiyao". However, overexploitation of the plant for economic purposes is pushing the species to the brink of extinction. Therefore, there is an urgent need to develop conservation strategies for this endangered species, for example, through assessment of its genetic structure and diversity. Here, we developed ten novel polymorphic microsatellite loci. The characteristics of these markers were assessed in 60 individuals from South China. The number of alleles per locus ranged from 4 to 12 , Observed and expected heterozygosity ranged from 0.303 to 0.969
\end{abstract}


and from 0.790 to 0.976 , respectively. These markers will therefore be useful tools for future population genetic studies and for the conservation of genetic resources of $P$. polyphylla var. yunnanensis.

Key words: Paris polyphylla var. yunnanensis; Genetic diversity; Microsatellites markers

\section{INTRODUCTION}

Paris polyphylla var. yunnanensis is a traditional Chinese medicinal plant that is listed as vulnerable by the IUCN. The herb is well-known for its analgesic and anti-inflammatory properties, most notably as an ingredient of the hemostatic compound "Yunnan Baiyao" (Wu et al., 2004). However, over-exploitation for economic purposes is pushing this species to the brink of extinction. Therefore, there is an urgent need to develop conservation strategies for this endangered species through the characterization of its genetic structure and diversity.

Microsatellite markers (SSRs) have been successfully used for population genetic diversity analysis because of their co-dominant inheritance and high levels of polymorphism (Varshney et al., 2005; Kalia et al., 2011) and used in investigations of many species of medicinal plants (Verma et al., 2013). To date, 12 polymorphic microsatellite loci have been reported in P. polyphylla var. yunnanensis (Zheng et al., 2012). Here, we report 10 new polymorphic microsatellite markers for this species and expect them to facilitate the further development of genetic conservation strategies.

\section{MATERIAL AND METHODS}

Sixty-two individuals were collected from Yunnan in South China and their identity confirmed by morphology. Genomic DNA was extracted from leaves using the cetyltrimethylammonium bromide method (Doyle and Doyle, 1987). A magnetic bead enrichment strategy was used to isolate the microsatellites (Nunome et al., 2006). Approximately $50 \mu \mathrm{g}$ genomic DNA was digested with Sau3AI (New England Biolabs, Beijing, China) for $4 \mathrm{~h}$ at $37^{\circ} \mathrm{C}$. The digested DNA was separated with centrifugal concentrators. Fragments 300-1000 bp in length were excised and recovered using the AxyPrep DNA Gel Extraction Kit (Axygen, Shanghai, China). The purified fragments were then ligated to two adaptor oligonucleotides (adaptor A: 5'-GATCGTCGACGGTACCGAATTCT-3'; adaptor B: 5'-GTCAAGAATTCGGTACCGTCG AC-3') with T4 DNA ligase (Takara, Dalian, China) overnight at $16^{\circ} \mathrm{C}$. The PCR products were then hybridized to biotinylated probes $(\mathrm{AC})_{15}$ or $(\mathrm{AG})_{15}$ to select fragments with microsatellites. Hybridization products were captured with streptavidin-coated magnetic beads (Promega, Beijing, China), and enriched by PCR. The PCR products were ligated into pEASY-T1 using a Cloning Kit (TransGene Biotech, China) and then transformed into DH5 $\alpha$ competent cells (TaKaRa). Ninety-eight positive clones were identified, 45 of which had microsatellite repeats. Thirty-seven clones were suitable for designing locus-specific primers using Primer Premier 3.0 (Rozen and Skaletsky, 2000).

Ten SSR primers were tested using the 62 Yunnan province individuals. Amplification was performed in a $20-\mu \mathrm{L}$ volume containing $75 \mathrm{ng}$ template DNA, $2.5 \mathrm{X}$ multiplex buffer, $1 \mathrm{U}$ Taq DNA polymerase (Microread, Beijing, China) and $5 \mu \mathrm{M}$ of each primer (Sangon, Shanghai, China), one of which was labelled with a fluorescent dye. Amplification conditions 
were $95^{\circ} \mathrm{C}$ for $5 \mathrm{~min}$, followed by 30 cycles at $94^{\circ} \mathrm{C}$ for $30 \mathrm{~s}, 56^{\circ} \mathrm{C}$ for $45 \mathrm{~s}$, and $72^{\circ} \mathrm{C}$ for 45 s; 10 cycles at $94^{\circ} \mathrm{C}$ for $30 \mathrm{~s}, 53^{\circ} \mathrm{C}$ for $45 \mathrm{~s}, 72^{\circ} \mathrm{C}$ for $45 \mathrm{~s}$ and a final extension at $72^{\circ} \mathrm{C}$ for 12 min. Fluorescently labeled fragments were visualized on an ABI Prism 377 DNA Sequencer with a GeneScan-500 ROX size standard (Applied Biosystems). Allele size was called with the GeneScan software ver. 3.7 (Applied Biosystems).

Cervus ver. 2.0 (Marshall et al., 1998) was used to calculate observed $\left(H_{\mathrm{O}}\right)$ and expected heterozygosity $\left(H_{\mathrm{E}}\right)$, to evaluate deviation from the Hardy-Weinberg equilibrium (HWE), and to obtain polymorphic information content (PIC) values. Deviations from Hardy-Weinberg equilibrium (HWE) and linkage disequilibrium (LD) were tested using GenePop 3.4 (Raymond and Rousset, 1995).

\section{RESULTS AND DISCUSSION}

Forty-five sequences were identified that contained microsatellites with perfect repeat motifs, and 37 of these microsatellites were suitable for designing locus-specific primers. In total, 10 loci were successfully amplified and showed high levels of polymorphism (Table 1). The number of alleles per locus ranged from 4 to 12 , with an average of $7 . H_{\mathrm{O}}$ ranged from 0.303 to 0.969 and $H_{\mathrm{E}}$ from 0.790 to 0.976 . PIC values ranged from 0.766 to 0.976 (mean $=$ 0.930). All ten loci were highly polymorphic (PIC > 0.5). Six loci (CL35, CL38, CL1, CL13, $C L 3$, and $C L 32)$ showed significant deviation from $\operatorname{HWE}(\mathrm{P}<0.05)$, probably due to an excess of homozygotes. Analyses using GenePop showed that significant LD was observed between two locus pairs, CL11 and CL37, and CL34 and CL47.

The microsatellite markers reported here will be of value for genetic diversity studies in P. polyphylla var. yunnanensis and will facilitate the future investigation of the population genetic structure in this species. Furthermore, we expect that these 10 markers will aid the development of efficient strategies for the conservation and management of the germplasm of this medicinal plant.

\begin{tabular}{|c|c|c|c|c|c|c|c|}
\hline GenBank accession No. & Primer sequence $\left(5^{\prime}-3^{\prime}\right)$ & Repeat motif & Size range (bp) & $N_{\mathrm{A}}$ & $H_{\mathrm{O}}$ & $H_{\mathrm{E}}$ & PIC \\
\hline \multirow[t]{2}{*}{ CL11 KR047182 } & F: GCTGGGCTAGGATTTTGGTA & & & & & & \\
\hline & R: GCAATTTTGAGCTGCTGACTC & $(\mathrm{GA})_{7} \ldots(\mathrm{GA})_{9} \ldots(\mathrm{GA})_{9}$ & 285-335 & 12 & 0.969 & 0.968 & 0.967 \\
\hline \multirow[t]{2}{*}{ CL35 KR047186 } & F: CCTCGACCGGAGTCCATAT & & & & & & \\
\hline & R: CGTTGTGCGGGTGATGA & $(\mathrm{AG})_{26}$ & $200-300$ & 7 & 0.818 & $0.96^{*}$ & 0.963 \\
\hline \multirow[t]{2}{*}{ CL37 KR047183 } & F: CCCGATCCCACCAGAGAAG & & & & & & \\
\hline & R: ACCCCGGTTTGGTAGGCTA & $(\mathrm{AG})_{8} \ldots(\mathrm{AG})_{20}$ & $200-300$ & 7 & 0.788 & 0.963 & 0.962 \\
\hline \multirow[t]{2}{*}{ CL38 KR047187 } & F: CGAACATGATCGGAGTACGG & & & & & & \\
\hline & R: CCGACAACATCGGACCTCAT & $(\mathrm{GA})_{15}$ & $200-300$ & 7 & 0.787 & $0.927^{*}$ & 0.922 \\
\hline \multirow[t]{2}{*}{ CL1 KR047184 } & F: GACGACGGCTATTGCTCC & & & & & & \\
\hline & R: AGCCCGTCGCCATTAGCT & $(\mathrm{AG})_{7} \ldots(\mathrm{AGC})_{6} \ldots(\mathrm{AG})_{18} \ldots(\mathrm{AG})_{5} \ldots$ & .. $300-480$ & 7 & 0.758 & $0.962^{*}$ & 0.961 \\
\hline \multirow[t]{2}{*}{ CL13 KR047188 } & F: GAAGCACCAGTTGGTGGAG & $(\mathrm{AG})_{30} \ldots(\mathrm{AG})_{12}$ & & & & & \\
\hline & R: GGGTCACCCTACCTTTCAGC & $(\mathrm{TC})_{6} \ldots(\mathrm{TC})_{23} \ldots(\mathrm{CT})_{6}$ & $150-340$ & 10 & 0.818 & $0.976^{*}$ & 0.976 \\
\hline \multirow[t]{2}{*}{ CL3 KR047185 } & F: AGCCATCTTCTTCGTTTGGC & & & & & & \\
\hline & R: CGAATCAACGGCGAGTGTC & $(\mathrm{CT})_{20}$ & $120-220$ & 6 & 0.485 & $0.953^{*}$ & 0.950 \\
\hline \multirow[t]{2}{*}{ CL34 KR047189 } & F: GGTGACGCCACAAAGAAGAC & & & & & & \\
\hline & R: CGTCGTGACCGCCTACTACT & $(\mathrm{AG})_{6} \ldots(\mathrm{AG})_{22}$ & $90-190$ & 7 & 0.697 & 0.950 & 0.945 \\
\hline CL32 KR047190 & R: GCACTCCATCATGACGAGAGT & $(\mathrm{TC})_{2}$ & $120-220$ & 7 & 0.879 & $0.904 *$ & 0.897 \\
\hline \multirow[t]{2}{*}{ CL47 KR047191 } & F: CGACGACGATTGCCTCC & & & & & & \\
\hline & R: TTCCСТCTCAACTGCCTGG & $(\mathrm{C})_{14} \ldots(\mathrm{CA})_{9} \ldots(\mathrm{T})_{7}$ & $100-130$ & 4 & 0.303 & 0.790 & 0.766 \\
\hline
\end{tabular}

$N_{\mathrm{A}}=$ number of observed alleles; $H_{\mathrm{O}}=$ observed heterozygosity; $H_{\mathrm{E}}=$ expected heterozygosity; $\mathrm{PIC}=$ polymorphism information content. *significant deviation from HWE after Bonferroni correction $(\mathrm{P}<0.05)$. 


\section{Conflicts of interest}

The authors declare no conflict of interest.

\section{ACKNOWLEDGMENTS}

Research supported by a grant from the Specialized Funds for Inspection and Quarantine Scientific Research on Germplasm Resources from General Administration of Quality Supervision, Inspection and Quarantine of China (AQSIQ, 2015), the Basic Scientific Research Foundation of the Chinese Academy of Inspection and Quarantine (\#2014JK010).

\section{REFERENCES}

Doyle JJ and Doyle JL (1987). A rapid DNA isolation procedure for small quantities of fresh leaf tissue. Phytochem. Bull. 19: 11-15.

Kalia RK, Rai MK, Kalia S, Singh R, et al. (2011). Microsatellite markers: an overview of the recent progress in plants. Euphytica 177: 309-334.

Marshall TC, Slate J, Kruuk LE and Pemberton JM (1998). Statistical confidence for likelihood-based paternity inference in natural populations. Mol. Ecol. 7: 639-655.

Nunome T, Negoro S, Miyatake K, Yamaguchi H, et al. (2006). A protocol for the construction of microsatellite enriched genomic library. Plant Mol. Biol. Rep. 24: 305-312.

Raymond $\mathrm{M}$ and Rousset $\mathrm{F}$ (1995). GENEPOP (version 1.2): population genetics software for exact tests and ecumenicism. J. Hered. 86: 248-249.

Rozen S and Skaletsky H (2000). Primer3 on the WWW for general users and for biologist programmers. Methods Mol. Biol. 132: 365-386.

Varshney RK, Graner A and Sorrells ME (2005). Genic microsatellite markers in plants: features and applications. Trends Biotechnol. 23: 48-55.

Verma NK, Kumar A, Deshwal RK, Tyagi V, et al. (2013). A current review on assessment of genetic analysis system for medicinal plants with microsatellites. Int. J. Curr. Res. Rev. 5: 1-11.

Wu SS, Gao WY, Duan HQ and Jia W (2004). Advances in studies on chemical constituents and pharmacological activities of Rhizoma paridis. Chin. Trad. Herb. Drugs 35: 344-346.

Zheng JY, Wang H, Chen XX, Wang P, et al. (2012). Microsatellite markers for assessing genetic diversity of the medicinal plant Paris polyphylla var. chinensis (Trilliaceae). Genet. Mol. Res. 11: 1975-1980. 